Original Article

\title{
FORMULATION AND IN VITRO EVALUATION OF AZILSARTAN MEDOXOMIL NANOSUSPENSION
}

\author{
NIZAR AWISH JASSEM ${ }^{\mathrm{a}}$, NAWAL AYASH RAJAB \\ ${ }^{a}$ Al-Rifai General Hospital, Thi-Qar Health Directorate, Ministry of Health, Iraq, bepartment of Pharmaceutics, College of Pharmacy, \\ University of Baghdad, Iraq \\ Email: pharmaceutical77@gmail.com
}

Received: 04 Apr 2017 Revised and Accepted: 19 May 2017

\section{ABSTRACT}

Objective: The objective of this study was to formulate and evaluate of the poorly soluble drug, azilsartan medoxomil into nanosuspension to increase the solubility and enhance the dissolution rate and then improve its bioavailability.

Methods: Nanosuspension of azilsartan medoxomil was prepared using solvent-antisolvent precipitation method using PVP-K30 as a stabilizer. Eight formulations were prepared to show the effect of different parameters in which four formulations show the effect of stabilizer concentration, three formulations show the effect of stirring speed and two formulations prepare to show the effect of the addition of co-stabilizer such as sodium lauryl sulphate (SLS) and tween 80. All these formulation are evaluated for their particle size and entrapment efficiency. The selected one was evaluated for zeta potential, scanning electron microscope (SEM), saturation solubility, and in vitro drug release.

Results: All the prepared formulations were in the nano size. The optimum concentration of the stabilizer was in the formulation when the drug: stabilizer ratio 1:1 and optimum stirring speed was $300 \mathrm{rpm}$. Dramatic effect on the particle size reduction was found by the addition of costabilizer (SLS) in formulation F3 that has P. S $157 \pm 0.0 \mathrm{~nm}$. The selected formula F3 showed an enhanced dissolution profile compared to the pure drug at all-time intervals.

Conclusion: The results show that the formulation that contain drug: PVP-K30: SLS in ratio 1:0.75:0.25 is the best one and can be utilized to formulate azilsartan medoxomil nanosuspension.

Keywords: Azilsartan medoxomil, Solubility, Bioavailability

(c) 2017 The Authors. Published by Innovare Academic Sciences Pvt Ltd. This is an open access article under the CC BY license (http://creativecommons.org/licenses/by/4.0/) DOI: http://dx.doi.org/10.22159/ijpps.2017v9i7.18917

\section{INTRODUCTION}

Drug solubility refers to the maximum amount of solute dissolved in the solvent under the specific condition of temperature, pressure and $\mathrm{pH}$. It has been known that solubility, dissolution and gastrointestinal permeability are important parameters that control its bioavailability [1]. The water solubility of a drug plays an important role in the absorption of the drug after oral administration. It is also useful in manipulating and testing of drug properties during the drug design and development process. It is critically important when the dissolution time is limited [2]

There are several formulation approaches are available to solve the problems of low aqueous solubility and increase the dissolution rate of hydrophobic drugs. Some of the conventional approaches are micronization, use of penetration enhancer or co-solvents, surfactant dispersion method, salt formation, etc., but the major problems of these techniques are limited advantages in solubility enhancement for poorly soluble drugs. Also precipitation, toxicity and altered pharmacological activity are another disadvantages of the conventional strategies [3-5]

Other additional approaches are vesicular systems like liposomes, dispersion of solids, emulsion and micro emulsion methods, and complexes with cyclodextrins, these methods show the beneficial effect as drug delivery system but they are not applicable to all the drugs molecules which consider the major problem to all these techniques [6].

Nanotechnology can be used as an alternative method to enhance drug solubility and solve the problems associated with various approaches of the conventional methods described earlier [7, 8]. A pharmaceutical nanosuspension is biphasic systems consisting of Nano sized drug particles stabilised by surfactants for either ora and topical use or parenteral and pulmonary administration. This technology is used for poorly soluble drugs that are insoluble in both water and oils. Particle size distribution in nanosuspensions is usually less than one micron with an ideal average particle size ranging between 200 and $600 \mathrm{~nm}$ [9].

Nanosuspensions are considered to be the best dosage form in the formulation of BCS class-II drugs since this technology results in the formulation that is having high dissolution velocity and increased saturation solubility [10]. Other advantages of nanosuspension are that it can be easy fabrication into a tablet or a capsule or dried nanosuspension form which can easily be redispersible [11].

Azilsartan medoxomil is [(5-methyl-2-oxo-1, 3-dioxol-4-yl) methyl 2-ethoxy-1-\{[2'-(5-oxo-4,5-dihydro-1,2,4-oxadiazol-3-yl)biphenyl-4yl]methyl $\}-1 H$-benzimidazole-7-carboxylate] with a molecular weight of $568.5 \mathrm{~g} / \mathrm{mol}$. Fig. (1) Shows the chemical structure of azilsartan medoxomil [12]

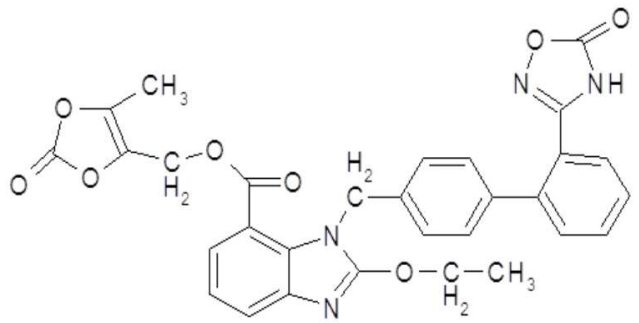

Fig. 1: Chemical structure of azilsartan medoxomil [12]

Azilsartan medoxomil appear like a white crystalline powder which is practically insoluble in water, freely soluble in methanol, soluble 
in acetic acid, slightly soluble in acetone and acetonitrile while it is very slightly soluble in 1-octanol. Azilsartan medoxomil has melting point 212-214 C, pKa 6.1 and $\log$ P 5.70. It is more lipophilic than candisartan $[13,14]$.

Azilsartan medoxomil (AZL-M) is a prodrug that it is rapidly hydrolyzed to the active metabolite, azilsartan, during the gastrointestinal absorption phase. It is a selective AT1 subtype angiotensin II receptor blocker (ARB) and is indicated for the treatment of mild to moderate essential hypertension [15]. Azilsartan reach its peak plasma concentration in about of 1.5 to $3 \mathrm{~h}$ after oral administration, with bioavailability from $50-55 \%$, the non-absorbable drug leads to diarrhea and gastric disturbances. It has a half-life of approximately $11 \mathrm{~h}$ and volume of distribution is $16 \mathrm{~L}$ [16].

The starting dose in adults is $40 \mathrm{mg}$ taken orally once daily and this may be increased to $80 \mathrm{mg}$ once daily when it is required [17]. AZL$M$ has shown pharmaceutical problems of water solubility. Because it is practically insoluble in water, the dissolution of AZL-M from its available dosage form after oral administration which is an important factor for its bioavailability is usually the rate-limiting step in the absorption process [18].

The aim of present study is to the formulation of azilsartam medoxomil as nanosuspension in order to improve its solubility and enhance in vitro dissolution rate.

\section{MATERIALS AND METHODS}

\section{Materials}

Azilsartan medoxomil (99\% pure) was purchased from Hangzhou Hyper Chemical Limited, China. Sodium lauryl sulfate (SLS) was purchased from S. D Fine-Chem limited Mumbai, India. Poly vinyl pyrrolidone k-30 was provided by Hangzhou Sunflower Technology Development Co., Ltd. China. All other chemicals and solvents were of analytical reagent grade, and deionized water also was used in this study.

\section{Method}

\section{Determination of $\lambda_{\max }$}

Ten milligrams of azilsartan medoxomel was dispersed in $100 \mathrm{ml}$ $0.1 \mathrm{~N} \mathrm{HCl} \mathrm{pH} 1.2$ to prepare $0.1 \mathrm{mg} / \mathrm{ml}$ stock solution. From this stock solution, a dilute $(10 \mu \mathrm{g} / \mathrm{ml})$ solution was prepared and scanned by UV spectrophotometer at the range of $200-400 \mathrm{~nm}$, The same steps were repeated with phosphate buffer $\mathrm{pH} 6.8$, water and methanol to obtain the $\lambda$ max of azilsartan medoxomel in these medium[19].

\section{Preparation of calibration curves}

Calibration curves of azilsartan medoxomil in $0.1 \mathrm{~N} \mathrm{HCl}$, phosphate buffer $\mathrm{pH}$ 6.8, water and methanol were constructed by preparing serial dilutions of the drug from $0.1 \mathrm{mg} / \mathrm{ml}$ stock solution for each medium. The prepared samples were analyzed spectrophotometrically at $\lambda_{\text {max }}$ in these media. The plot of absorbance vs. concentration is done and beer's range was determined [20]. The results were analyzed in triplicate and standard division was represented.

\section{Determination of saturation solubility of azilsartan medoxomil}

Saturation solubility of azlisartan medoxomil was determined in (water, methanol, 0.1N HCL pH 1.2 and phosphate buffer $(\mathrm{pH} 7.4$ and 6.8 solution). Excess amount of azilsartan medoxomil was added to $10 \mathrm{ml}$ of each media and kept in an incubator shaker at $25 \pm 0.5^{\circ} \mathrm{C}$ and after $48 \mathrm{~h}$, solution was centrifuged at $5000 \mathrm{rpm}$ for $15 \mathrm{~min}$. Supernatants were filtered and diluted with the respective solution. Absorbance was measured (at wave length specific for each media) using (UV) spectrophotometer and solubility was calculated from calibration curves [21,22]. Each sample was analyzed in triplicate.

\section{Preparation of azilsartan medoxomil nanosuspension by precipitation method}

Nanosuspension precipitation method is used to prepare oral nanosuspension of azilsartan medoxomil using different concentration of stabilizer and co-stabilizer. In brief, $40 \mathrm{mg}$ of azilsartan medoxomil was dissolved in an organic solvent $(3 \mathrm{ml}$ methanol). Deionized water containing stabilizer (PVP K30) alone in different concentration or in combination with co-stabilizer (tween 80 or SLS), which acts as the antisolvent system. This was followed by the addition of the organic solution into the antisolvent solution at a very slow rate $(1 \mathrm{ml} / \mathrm{min})$ by the help of a syringe pump, under mechanical agitation of different speeds using homo disperser. Then transfer to hot plate magnetic stirrer (Stuart U. K) for $60 \mathrm{~min}$ at $50 \pm 1{ }^{\circ} \mathrm{C}$ to allow organic solvent to evaporate and get the desired nanosuspension. [23]. The batches were prepared according to the formulation design (table 1 ).

Table 1: Composition of azilsartan medoxomil nanosuspensions

\begin{tabular}{|c|c|c|c|c|c|c|c|c|}
\hline Substance & F1 & F2 & F3 & F4 & F5 & F6 & F7 & F8 \\
\hline AZL-M (mg) & 40 & 40 & 40 & 40 & 40 & 40 & 40 & 40 \\
\hline PVP-K30 (mg) & 20 & 30 & 30 & 30 & 40 & 40 & 40 & 60 \\
\hline SLS (mg) & - & - & 10 & - & - & - & - & - \\
\hline Tween $80(\mathrm{ml})$ & - & - & - & $0.01 \mathrm{ml}$ & - & - & - & - \\
\hline Methanol (ml) & $3 \mathrm{ml}$ & $3 \mathrm{ml}$ & $3 \mathrm{ml}$ & $3 \mathrm{ml}$ & $3 \mathrm{ml}$ & $3 \mathrm{ml}$ & $3 \mathrm{ml}$ & $3 \mathrm{ml}$ \\
\hline Water (ml) & $40 \mathrm{ml}$ & $40 \mathrm{ml}$ & $40 \mathrm{ml}$ & $40 \mathrm{ml}$ & $40 \mathrm{ml}$ & $40 \mathrm{ml}$ & $40 \mathrm{ml}$ & $40 \mathrm{ml}$ \\
\hline Stirring speed (rpm) & 3500 & 3500 & 3500 & 3500 & 3500 & 1200 & 300 & 3500 \\
\hline
\end{tabular}

\section{Lyophilization of selected nanosuspension}

The selected formulation of the prepared azilsartan medoxomil nanosuspension was lyophilized (vacuum freeze dryer, Labconco, USA) using mannitol as a cryoprotectant (1:5 ratio-total solid content: Mannitol). Briefly, (five times the quantity of total solid content in nanosuspension). The nanosuspension was then kept in the freezer for a suitable time. Afterwards, the frozen nanosuspension was directly placed in the freeze dryer chamber and allowed to be lyophilized over $48 \mathrm{~h}$ at $20^{\circ} \mathrm{C}$ and $0.03 \mathrm{mbar}$ pressure [24].

\section{Evaluation of the prepared nanosuspension}

\section{Particle size and size distribution}

Particle size determination was done by using Nano Brook 90Plus particle size analyzer (Brookhaven instruments. USA) which is a dynamic light scattering, works by measuring the intensity of light scattered by the molecules in the sample as a function of time, at scattering angle $90^{\circ}$ and a constant temperature of $25^{\circ} \mathrm{C}$. The Nano Brook 90Plus particle size analyzer provides different choices. The important one is the determination of an average diameter (Eff. Dia.) and a measure of the polydispersity which are sufficient for many applications [25].

\section{Determination of entrapment efficiency (EE) of nanosuspension}

$10 \mathrm{ml}$ of nanosuspension was centrifuged at $5000 \mathrm{rpm}$ for $20 \mathrm{~min}$. The supernatant solution was filtered and separated. $1 \mathrm{ml}$ of this filtrate was diluted with water and the absorbance at maximum $\lambda$ max was measured by UV spectrophotometer using water as blank [26]. The amount of free drug in the formulations was measured and the entrapment efficiency is then calculated from Eq.1

$$
\text { E. } \mathrm{E} \%=\frac{\text { (Total drug in formula-free drug) } * 100}{\text { Total drug in formula }} \ldots \ldots . . \text { (1) }
$$


The results were analyzed in triplicate and standard deviations are reported.

\section{Zeta potential}

Zeta potential of the selected formulation of azilsartam medoxomil nanosuspension was measured using The Nano Brook 90Plus zeta seizer (Brookhaven Instruments USA). Before analysis, the samples were diluted 10 times with solvent. A zeta potential value of $\pm 30 \mathrm{mV}$ is required as a minimum for physically stable nanosuspension stabilised by electrostatic repulsion only. While zeta potential of about $\pm 20 \mathrm{mV}$ is sufficient to stabilise the nanosuspension system stabilized by a combination of steric and electrostatic stabilisation $[27,28]$.

\section{In vitro dissolution profile of nanosuspension}

In vitro drug release for nanosuspension was done by dialysis bag method using himedia dialysis membrane (MWCO $12 \mathrm{KD}$ ). Volume containing $40 \mathrm{mg}$ of azilsartan medoxomil of optimized formulations of nanosuspension was placed in pretreated dialysis bag and drug release was done using USP dissolution apparatus II containing $900 \mathrm{ml}$ of dissolution medium at $37 \pm 0.5^{\circ} \mathrm{C}$. The speed of the paddle was $100 \mathrm{rpm}$. The optimized formulation of azilsartan medoxomil nanosuspension was subjected to the drug release studies in both media of $0.1 \mathrm{~N} \mathrm{HCl}(\mathrm{pH} 1.2)$ and phosphate buffer $(\mathrm{pH} \mathrm{6.8)} \mathrm{in}$ comparison with pure drug. Samples $(5 \mathrm{ml})$ were withdrawn at regular intervals of $10 \mathrm{~min}$ for $90 \mathrm{~min}$ and replaced with fresh dissolution medium. Samples were filtered and assayed spectrophotometrically on UV spectrophotometer at $248 \mathrm{~nm}$ wavelength. For each formulation, the experiment was repeated in triplicate $[26,29]$.

\section{Scanning electron microscopy (SEM)}

The pure drug powder of azilsartan medoxomil was confirmed by direct deposition of powder as thin film on double-sided carbon tape, while SEM for the liquid of the selected formulation of the prepared nanosuspension was confirmed by the droplet evaporation technique and photographs were taken at different magnification [10]. A droplet of liquid was deposited on a double-sided carbon tape and dried at room temperature using a Vega/TESCAN scanning electron microscope operated with a secondary detector at different acceleration voltage and at different magnification [30].

\section{X-ray powder diffraction (XRPD)}

Powder X-ray diffraction can be used to confirm the crystalline nature of materials. So, this information is used to verify whether the substances are crystalline or amorphous. The diffractograms of azilsartan medoxomil and lyophilized powders of the selected formulation were obtained for analysis. The study was confirmed by using Shimadzu XRD-6000 powder X-ray diffractometer at continuous scan range of 10-80 degree. The operating voltage was $40(\mathrm{kV})$ and current $30 \mathrm{~mA}[31,32]$.

\section{Fourier transforms infrared spectroscopy (FTIR)}

The FTIR spectra of pure azilsartan and lyophilized powder of the selected formula were obtained using FTIR spectrophotometer (FTIR-8300 Shimadzu, Japan) by potassium bromide (KBr) pellet method. This study was achieved to identify any sign of interaction between the drug and stabiliser used. The spectrum obtained was in between the wave number of 4000-400 cm-1 [33].

\section{Statistical analysis}

The results were expressed as mean $\pm \mathrm{SD}$ and were analysed statistically by one-way analysis of variance (ANOVA) using Graph Pad Prism V5.04 software (San Diego, CA, USA) at level of $(\mathrm{p}<0.05)$.

\section{RESULTS AND DISCUSSION}

\section{Determination of $\lambda$ Max}

The analysis of UV spectra of azilsartan medoxomil in, HCL buffer $\mathrm{pH}$ 1.2 and water with $0.5 \%$ Tween 80 , and Phosphate buffer $\mathrm{pH} 6.8$ shows the same $\lambda \max 248 \mathrm{~nm}$ while it was $250 \mathrm{~nm}$ in methanol which similar to the published one as shown in fig. $2[34,35]$.

\section{Calibration curves of azilsartan medoxomil}

The constructed calibration curves of azilsartan medoxomil in methanol, water, $\mathrm{HCl}$ buffer $\mathrm{pH} 1.2$ with $0.5 \%$ Tween 80 , and Phosphate buffer pH 6.8 are shown in fig. 3. A straight line was obtained by plotting the absorbance versus concentration with a high coefficient of determination. This indicates that the calibration curve obeys Beer's law within the range of concentration used.

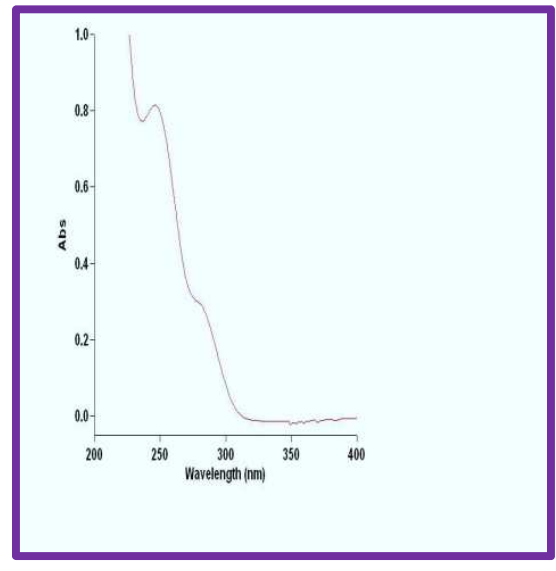

A

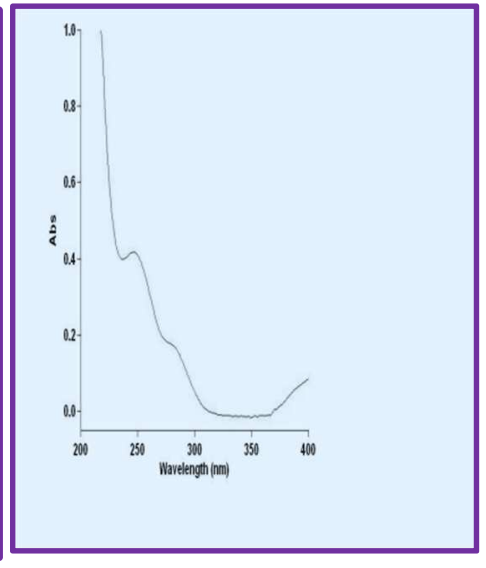

B

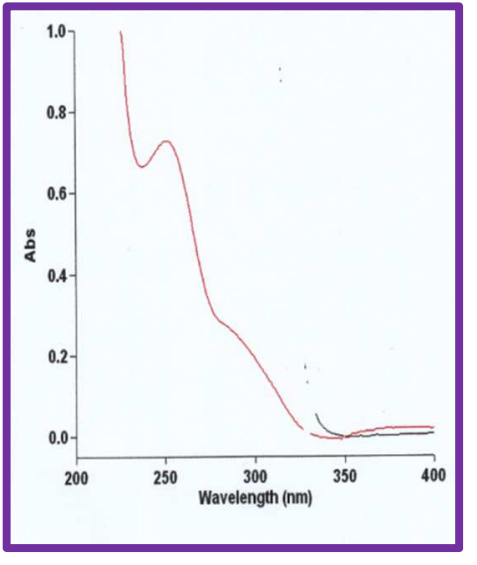

C

Fig. 2: UV Spectrum of azilsartan medoxomil in A-phosphate buffer pH 6.8 B-0.1N HCl and C-methanol

\section{Saturation solubility of azilsartan medoxomil}

The poor solubility of azilsartan medoxomil that determined is in agreement with published researches as shown in table 2, also the results shows that an increase in $\mathrm{pH}$ resulted in an increase in the solubility of azilsartan medoxomil as showing in the figure; this is because it is an acidic drug $(\mathrm{pKa}=6.1)$.

Table 2: Saturation solubility of azilsartan medoxomel in different media

\begin{tabular}{lllll}
\hline Solvent & PH 1.2 & PH 6.8 & PH 7.4 & Water \\
\hline Solubility $(\mu \mathrm{g} / \mathrm{ml})$ mean $\pm \mathrm{SD}^{*}$ & $20.305 \pm 0.11$ & $374 \pm 0.5$ & $1033 \pm 1.2$ & $16.1 \pm 0.1$ \\
\hline
\end{tabular}

*SD standard deviation from mean, $\mathrm{n}=3$ 


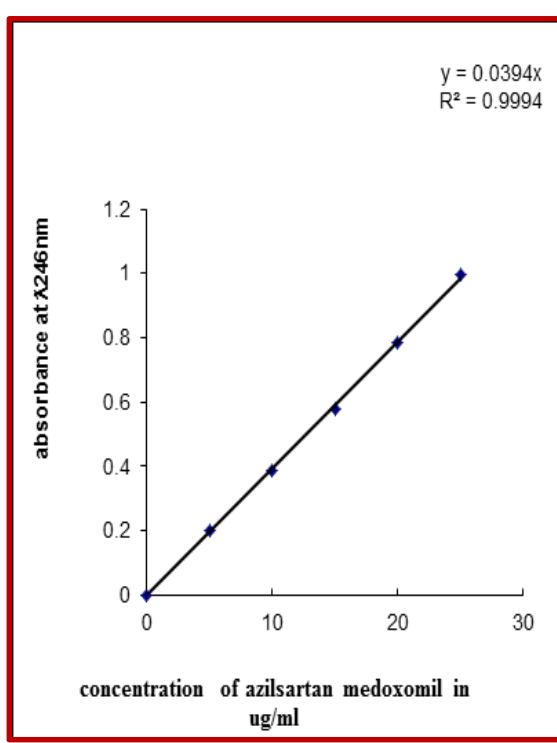

A

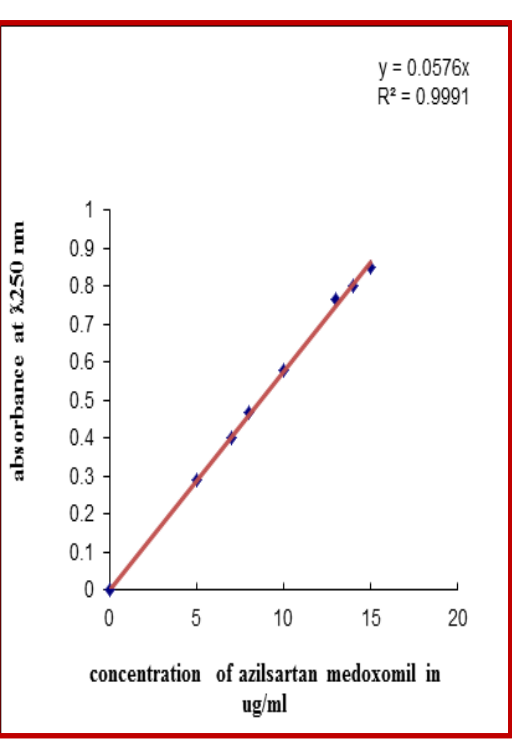

B

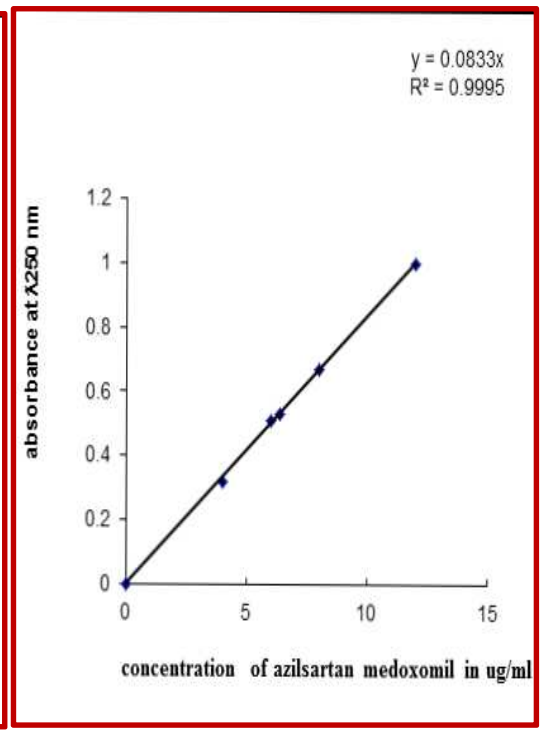

C

Fig. 3: Calibration curve of azilsartan medoxomil in A-in $0.1 \mathrm{~N} \mathrm{HCl}$, pH 1.2 B-in phosphate buffer $\mathrm{pH} 6.8$ and C-in water with $0.5 \%$ tween (Results are expressed as mean, $n=3$ )

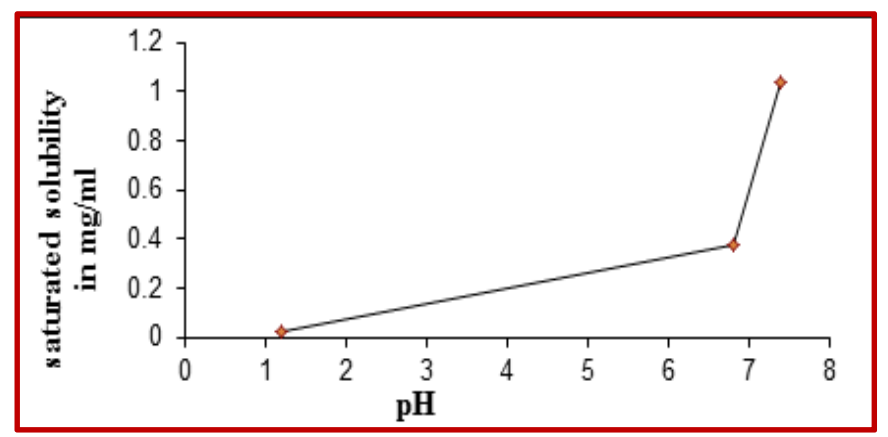

Fig. 4: Saturation solubility of azilsartan medoxomil in different pH (Results are expressed as mean, $n=3$ )

\section{Particle size analysis and polydispersity index measurement}

The effect of different parameters on the particle size and polydispersity index was studied using eight different formulations. All the prepared formulations were in the Nano size. The mean particle size (effective diameter) for formulations varied in the narrow range from $157 \pm 0.0 \mathrm{~nm}$ to $610.6 \pm 0.0 \mathrm{~nm}$.

The particle size and PDI for different formulations of different parameters is showing in table 3

Table 3: The particle size, PDI, free drug and \% entrapment efficiency (E. E \%) of different formulations

\begin{tabular}{|c|c|c|c|c|c|c|}
\hline Formula no. & Stabilizer & Drug: stabilizer: co-stablizer ratio & Stirring speed & P. S \pm SD* & PDI & E. E\% $\%$ SD* \\
\hline F1 & PVP K30 & $1: 0.5$ & 3500 & $470.5 \pm 0.0$ & 0.252 & $83 \pm 0.14$ \\
\hline $\mathrm{F} 2$ & PVP K30 & $1: 0.75$ & 3500 & $421.2 \pm 0.0$ & 0.005 & $83.19 \pm 0.1$ \\
\hline F3 & PVPK30:SLS & $1: 0.75: 0.25$ & 3500 & $157 \pm 0.0$ & 0.005 & $95.8 \pm 0.2$ \\
\hline F4 & $\begin{array}{l}\text { PVPK30: } \\
\text { Tween80 }\end{array}$ & 1:0.75:0.25 & 3500 & $190.8 \pm 0.0$ & 0.005 & $97.1 \pm 0.2$ \\
\hline F5 & PVP K30 & $1: 1$ & 3500 & $324.3 \pm 0.0$ & 0.233 & $88.259 \pm 0.1$ \\
\hline F6 & PVP K30 & $1: 1$ & 1200 & $317.3 \pm 0.0$ & 0.005 & $90.75 \pm 0.3$ \\
\hline F7 & PVP K30 & $1: 1$ & 300 & $293.1 \pm 0.0$ & 0.315 & $90.97 \pm 0.1$ \\
\hline F8 & PVP K30 & $1: 1.5$ & 3500 & $610.6 \pm 0.0$ & 0.182 & $91.37 \pm 0.2$ \\
\hline
\end{tabular}

*SD standard deviation, $\mathrm{n}=3$

Effect of stabilizer concentration on the particle size and polydisperisity index

Four formulations were used to show this effect F1, F2, F5 and F8. The optimum concentration was in the formulation of F5 which has particle size $324.2 \pm 0.0 \mathrm{~nm}$. Also these formulation show PDI in the range of $0.05-0.252$ and this low value will indicate good stability of the nanosuspension. The effect of the drug to stabilizer radio show in the fig. 5. The choice of suitable stabilizers and its concentration are the most important factors to control the size and stability of the nanosuspension during nanoprecipitation methods [36, 37] 
In our work; PVP-K30 was used at different concentration (table 1). The results showed that particle size is reduced with the increasing of stabilizer concentration as the particle size of formula F1 which contains 1:0.5 of drug: pvp-k30 ratio was $470.5 \pm 0.0 \mathrm{~nm}$ compared with $324.3 \pm 0.0 \mathrm{~nm}$ for F5 which contains 1:1 ratio of drug: stabilizer. the reason behind this is that high stabilizer concentration decreases surface tension and stabilizes newly developed surfaces during precipitation process and produce nanosuspension of smaller particles size [38]. Also, low or insufficient concentration of stabilizer will cause instability and recrystallization [39]. This could be attributed to the increase in the molar substitution ratio (MSR) of the polymer per drug. The increase of the hydrophilic corona surrounding the polymer to protect the nanoparticles enhances the stability and prevents particles from aggregation $[40,41]$.

On the other hand, the particle size increased with the high concentration of PVP-K30 which might be due to the higher viscosity of the resulting solution that might hinder particle movement during stirring as in formulation F8 which has particle size of $610.6 \pm 0.0 \mathrm{~nm}$. The polydispersity index (PI) values were ranged from 0.05-0.356 which indicates acceptable uniformity level for all the prepared formulations [42]. Narrower range of particles size will minimizes the difference between active agent concentration and the surrounding environment. As a result, the Ostwald ripening phenomenon will be inhibited [43].

Effect of stirring speed on the particle size and polydispersity index of prepared nanosuspension

Three different speeds 3500,1200 and $300 \mathrm{rpm}$ were used to prepare three formulations F5-F7 to show this effect. In this study the optimum speed at a drug to stabilizer ratio 1:1 was found to be $300 \mathrm{rpm}$ that produce mean particle size $293.1 \pm 0.0 \mathrm{~nm}$. PDI of these formulations was in the range of 0.233-0.315. This effect is shown in fig. 6 .

Effect of addition co-stabilizer on particle size and polydispersity index

Two different stabilizers (SLS and Tween 80) in the ratio of drug: stabilizer: co-stabilizer 1: 0.75: 0.25 in formulations F3 and F4 were used to show this effect. The effect of SLS was more prominent than the effect of tween 80 on particle size in this study which produce nanosuspension of particle size $157 \mathrm{~nm}$ as compared with formulation F2 without costabilizer 421.2 and F4 that contain tween 80 of $190.8 \mathrm{~nm}$. Usually, a combination of homopolymer (PVP-K30) with ionic surfactant (SLS) is required to provide repelling forces and concomitant maintenance of particle stabilization and crystallization balance [44]. This effect is shown in figure7. These findings are in accordance with Kumar et al. who had lower particle sizes and better stability when stabilized the formulation with surfactant mixtures compared with formulations with only one surfactant [45].

It could be inferred from the results that there was a significant impact of the drug to polymer ratio, stirring speed and addition of co-stabilizer on the mean particle size of the drug loaded nanosuspensions and PDI. The addition of the surfactant on the particle size and PDI will be the formula no F3 which has the lowest mean particle size $(157.0 \pm 0.0 \mathrm{~nm})$ and this formula is selected for lyophilization and further stud. The mean particle sizes of the F3 formulation and their size distribution graph was shown in fig. 8.

Effect of stablizer concentration on PS

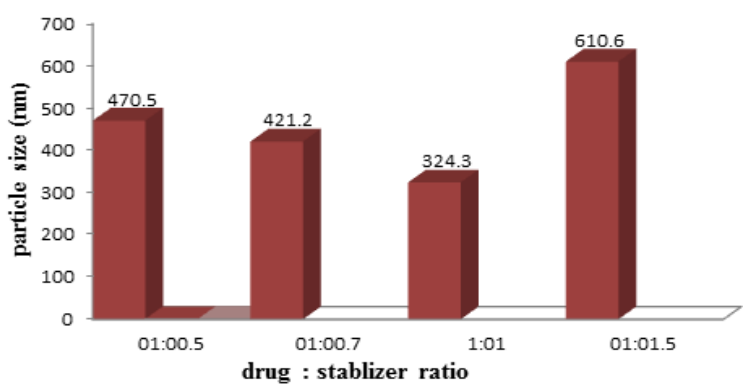

Fig. 5: Effect of stabilizer concentration on the particle size of nanosuspension (Results are expressed as mean, $n=3$ )
Effect of stirring speed on P.S

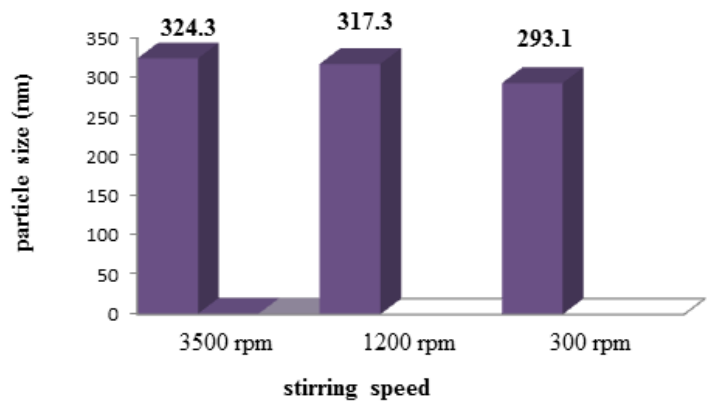

Fig. 6: Effect of stirring speed on particle size (Results are expressed as mean, $n=3$ )

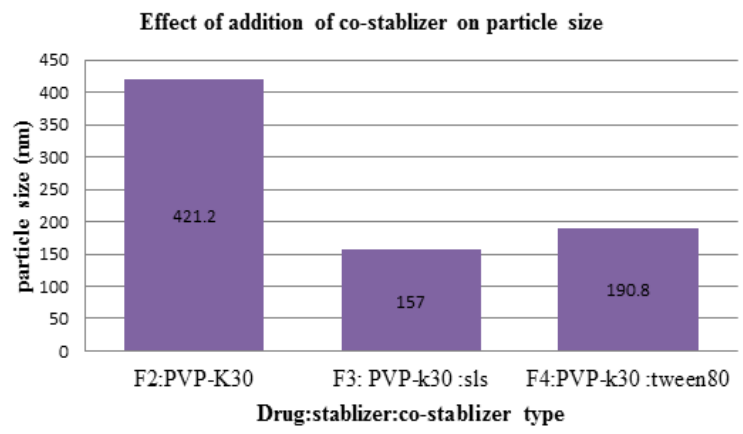

Fig. 7: Effect of addition of co-stabilizer on particle size (Results are expressed as mean, $n=3$ )

\section{Drug entrapment efficiency}

The Percentage drug entrapment efficiency of all the formulations was calculated and the results were tabulated in table (3). The drug entrapment efficiency of F3 and F4 was high when compared to other formulations. This may be due to the presence of optimum polymer and optimum tween 80 and SLS concentrations, comparing the formulations F1, F2, F5 and F6, it is clear that increase in polymer concentration increased the drug entrapment efficiency. Fig. 9 show the drug entrapment efficiency of a different formulation of azilsartan medoxomil nanosuspension. The concentration of stabilizer used are the most effective factor on entrapment efficiency and this agree with that obtained by Patil et al. who formulate spry dried chitosan nanoparticles containing doxorubicin [46].

\section{Zeta potential}

The zeta potential for the selected formulation of azilsartan medoxomil nanosuspension was- $127.17 \mathrm{mV}$ as shown in fig. 10 . The charge was negative due to adsorbed SDS and PVP-k30 on the drug particles; however the high zeta potential proposes that the nanosuspension was adequately stabilized. It reflects the electrical potential of particles and is influenced by the composition of the particle and the medium in which it is dispersed. Zeta potential gives certain information about the surface charge properties and further the long-term physical stability of the nanosuspensions. The obtained value for selected formulation indicates stable nanosuspension [47].

\section{Saturation solubility of freeze drying nanosuspension}

The batch F3 (AZL-M: PVP-K30: SLS 1:0.75:0.25) was selected for freeze drying since it had the small particle size and lowest polydispersity index. Using mannitol as the cryoprotectant resulted in the formation of a white spongy, cotton-like material upon lyophilization. Mannitol containing samples showed good redispersibility upon manual shaking. The saturation solubility of the lyophilized powder of the selected formula F3 was increased significantly. It increases to $11 \pm 0.2$ folds in $\mathrm{pH} 1.2$ and to $21.1 \pm 0.4$ folds in $\mathrm{pH} 6.8$ 


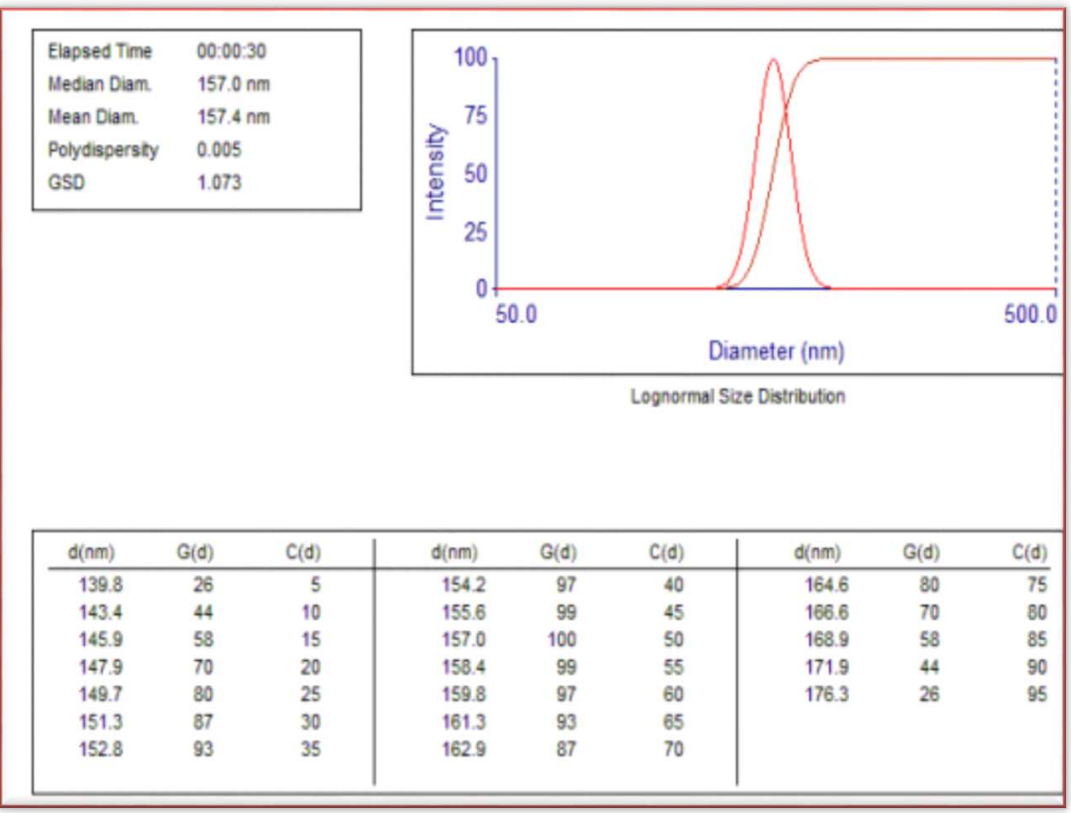

Fig. 8: particle size distribution of the selected formula (F3)

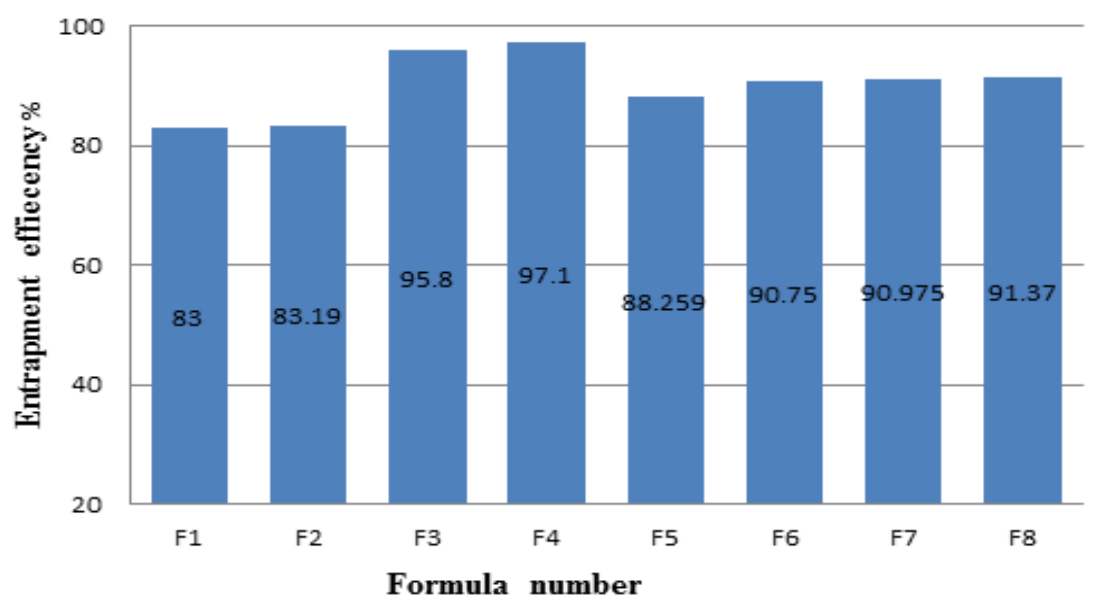

Fig. 9: Drug entrapment efficiency of the prepared formulation of azilsartan medoxomil nanosuspension (Results are expressed as mean, $n=3$ )

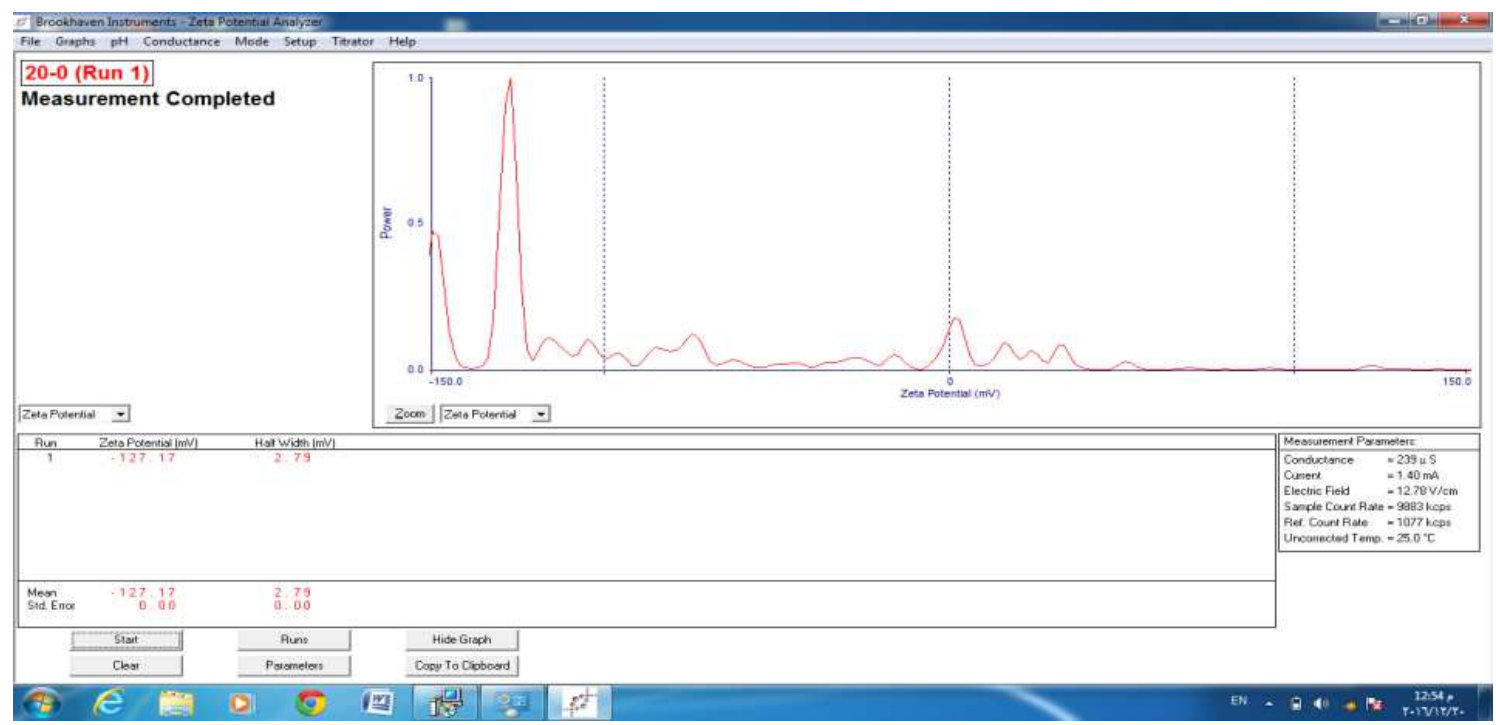

Fig. 10: Zeta potential of the selected formula (F3) 


\section{In vitro drug release}

In vitro drug release profiles of AZL-M pure drug, nanosuspension of selected formula (F3) are shown in fig. 11. The release of AZL-M from the nanosuspension of selected formulation was higher than the release profile of pure drug in $90 \mathrm{~min}$. The \%CDR of the selected formula F3 was more than $80 \%$ in less than 30 min in both $0.1 \mathrm{~N} \mathrm{HCl}$ and phosphate buffer pH 6.8 media as compare to less than $14 \%$ and $28 \%$ of pure drug in the same media respectively. This will indicate that the dissolution rate of the prepared nanosuspension is enhanced. Factors that contributing to a fast release were large surface area due to small particle size, high diffusion coefficient (small molecular size), low matrix viscosity and short diffusion distance of the drug [45].

\section{Scanning electron microscope}

The SEM of pure azilsartan medoxomil is presented in fig. (12) at 100x and 500x magnification. The particles of azilsartan were large in size(from 50-350um) and has irregular shape and when the picture is closer at 500x and more of magnification it would illustrate the rough surface of azilsartan particles. while the images of the SEM at different magnification for that of the selected formula of the nanosuspension (F3) is represent in fig. (13) and it indicate uniform submicron sized particles and results also show nearly spherical shaped nanoparticles and a size within the nano size and this micrograph was in agreement with those measured by particle size distribution [48].

\section{Powder X-ray diffraction analysis (PXRD)}

PXRD patterns of azilsartan medoxomil as a pure drug showed sharp diffraction peaks in the fig. (14) and this indicate the crystalline nature of the pure azilsartan medoxomil. azilsartan medoxomil show intense crystalline peaks at $2 \theta$ from $13^{\circ}$ to $27^{\circ}$, and the strongest three peaks were $23^{\circ}, 21^{\circ}$ and $20^{\circ}$. However, these characteristic peaks disappeared in the pattern of lyophilized powder of the selected formulations (F3) as seen in fig. (15) Producing a diffused pattern of very low intensity peaks and shifting to a lower degree and we characterized by the complete absence of any diffraction peak corresponding to crystalline azilsartan medoxomil. These results provide that the azilsartan medoxomil in the lyophilized powder is in an amorphous state [49].

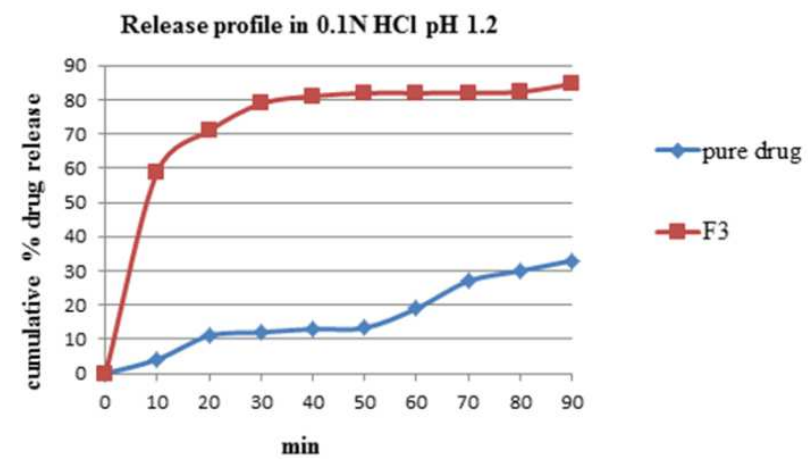

A

Release profile in phosphate buffer $\mathrm{pH} 6.8$

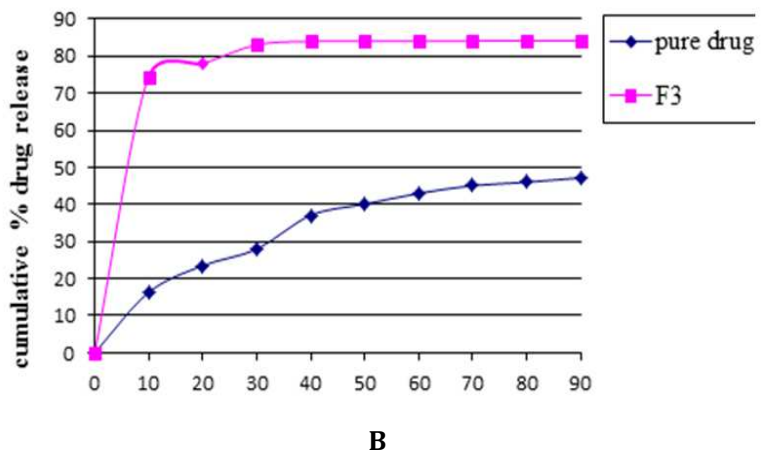

Fig. 11: In vitro drug release profile A-In 0.1N HCl B-In phosphate buffer $\mathrm{pH} 6.8$ at $37 \pm 0.5^{\circ} \mathrm{C}$ (Results are expressed as mean, $n=3$ )

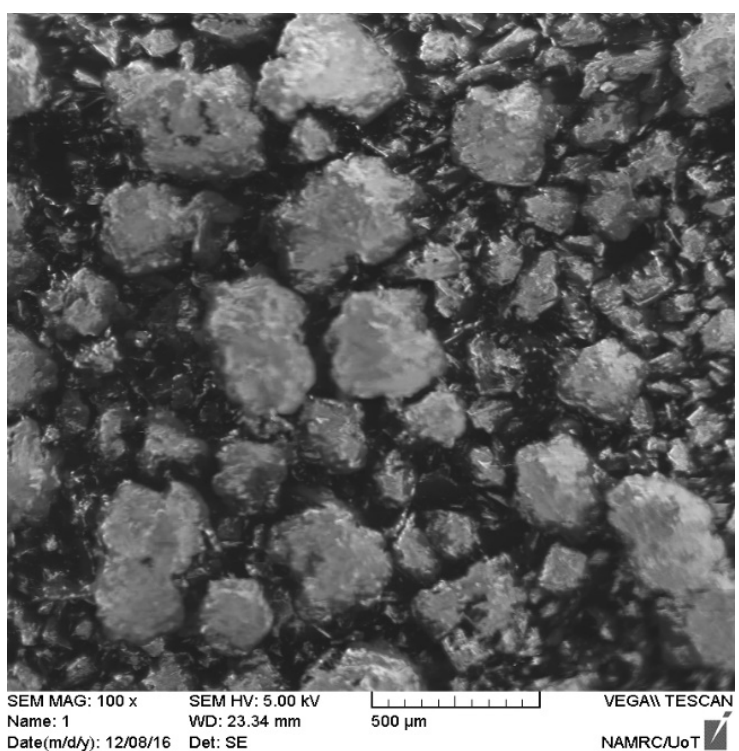

A

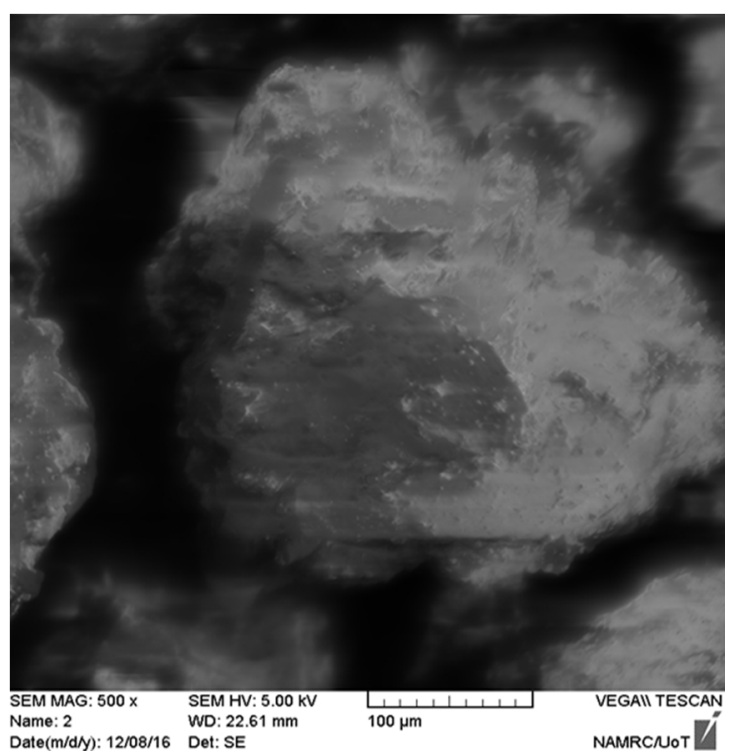

Fig. 12: SEM of pure azilsartan medoxomil A): $100 \mathrm{X}$ B): $500 \mathrm{X}$

\section{Fourier transforms infrared spectroscopy (FTIR)}

The FTIR spectra of pure azilsartan medoxomil is shown in fig. 16 and that of the lyophilized powder of the selected formula (F3) is shown in fig. 17. FTIR spectra of AZL-M nanosuspention show no change in shifting of the position of the major functional groups and this will indicate there is no major interaction between the drug and the stabilizer PVP K-30 and other excipients (SLS) used in the formulation [50]. 


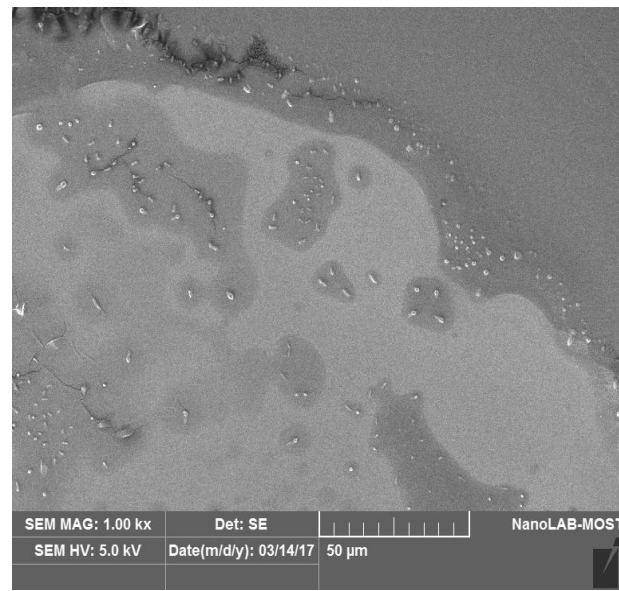

A

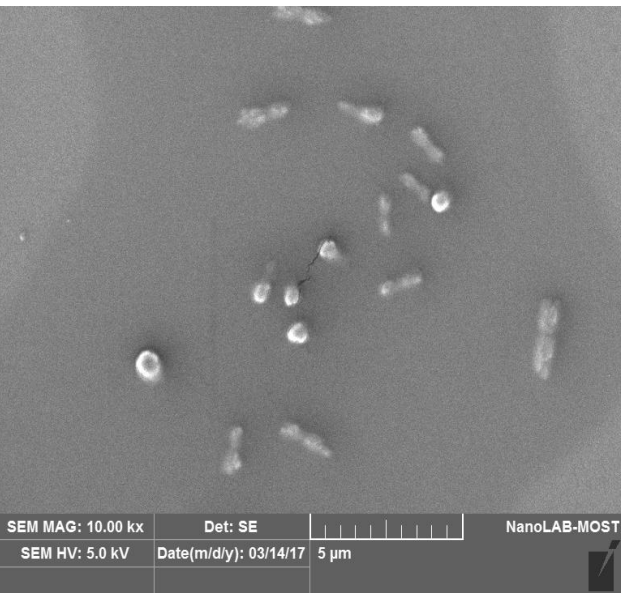

B

Fig. 13: SEM of selected formula F3 A):1kx B): $10 \mathrm{kx}$

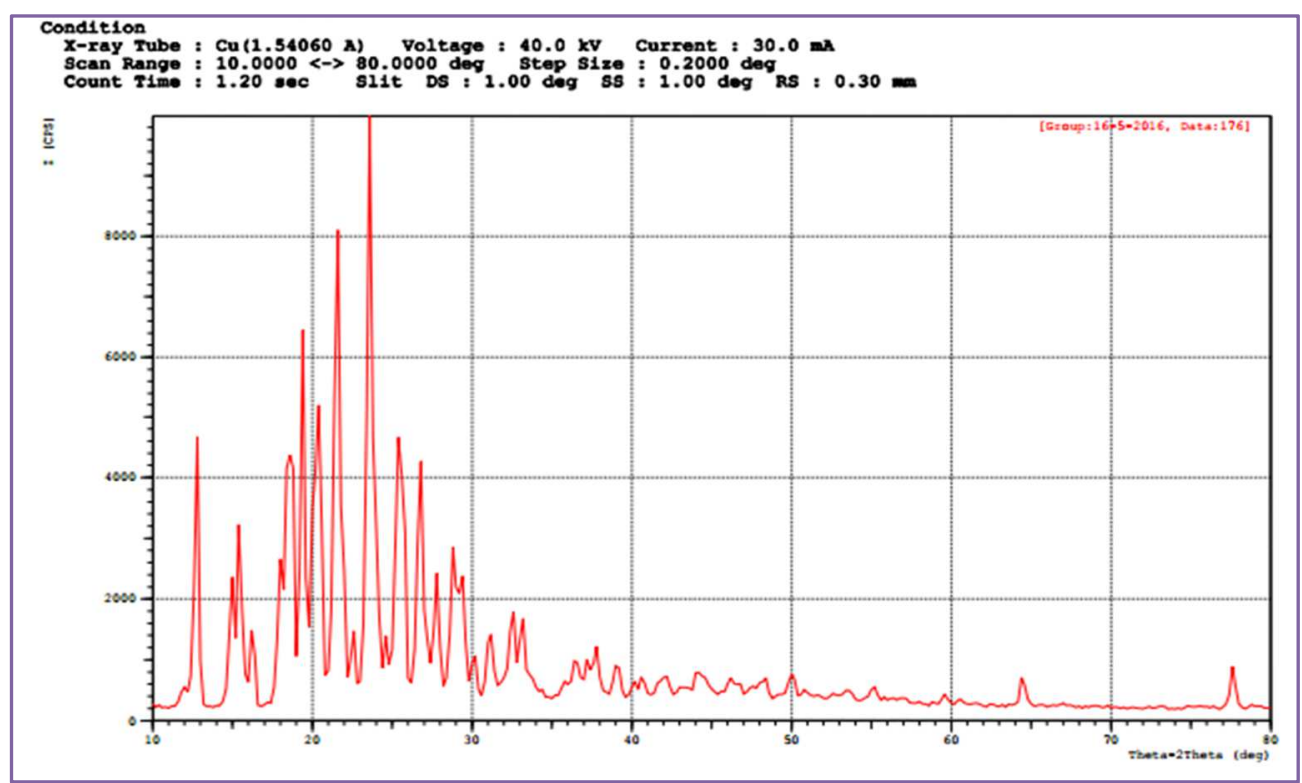

Fig. 14: PXRD of pure azilsartan medoxomil

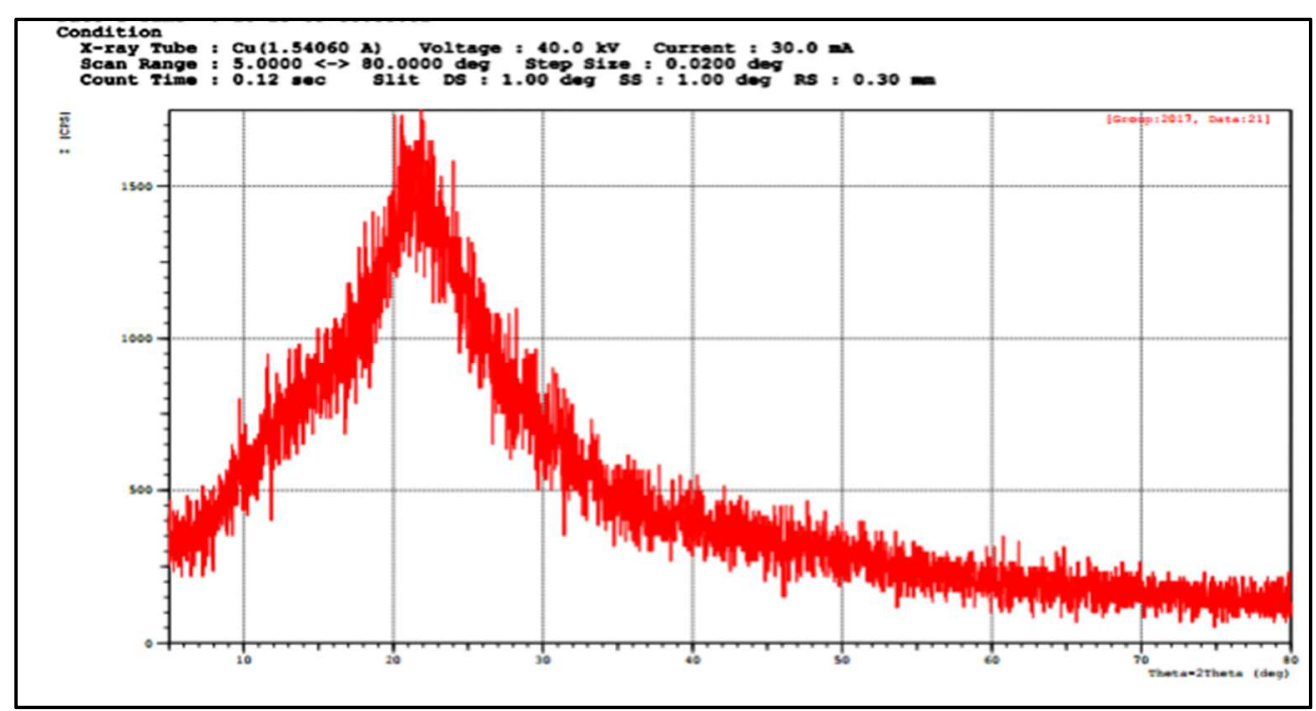

Fig. 15: PXRD of the selected formula F3 


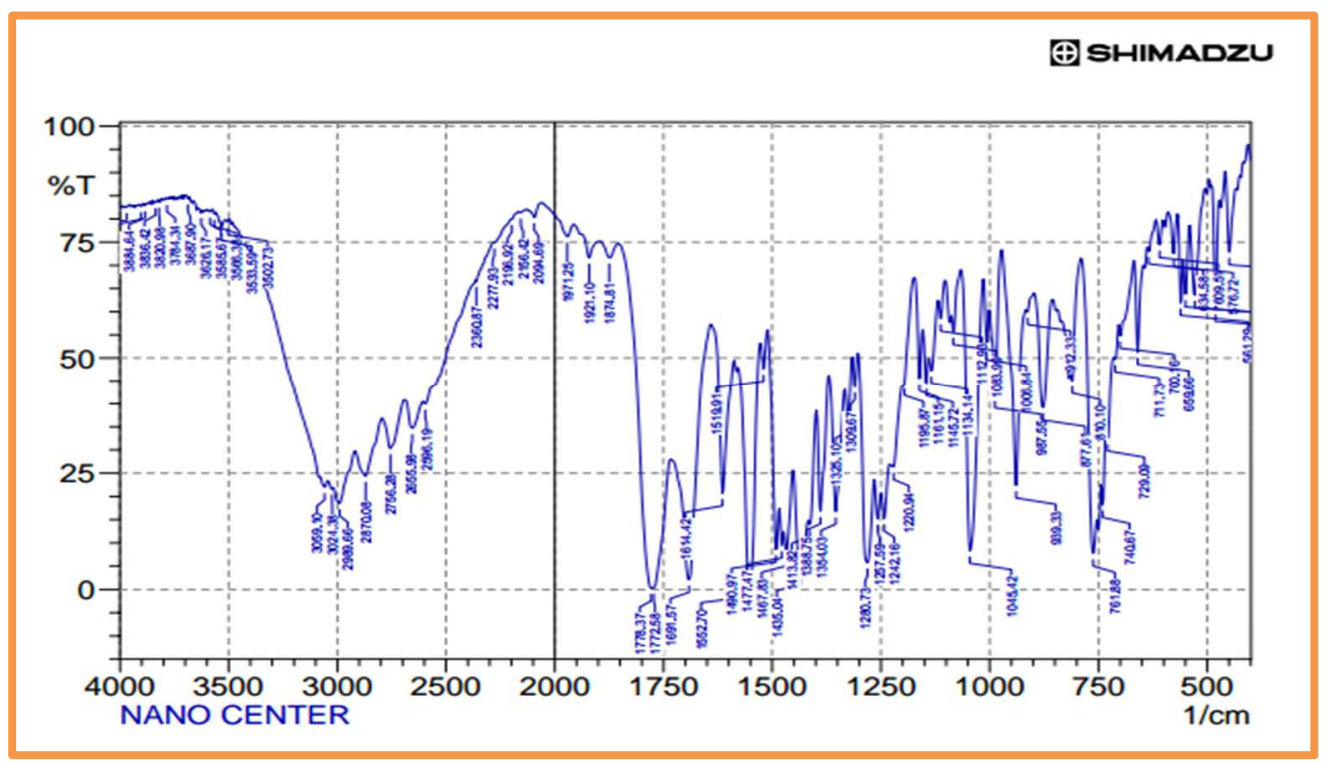

Fig. 16: FTIR spectrum of azilsartan medoxomil

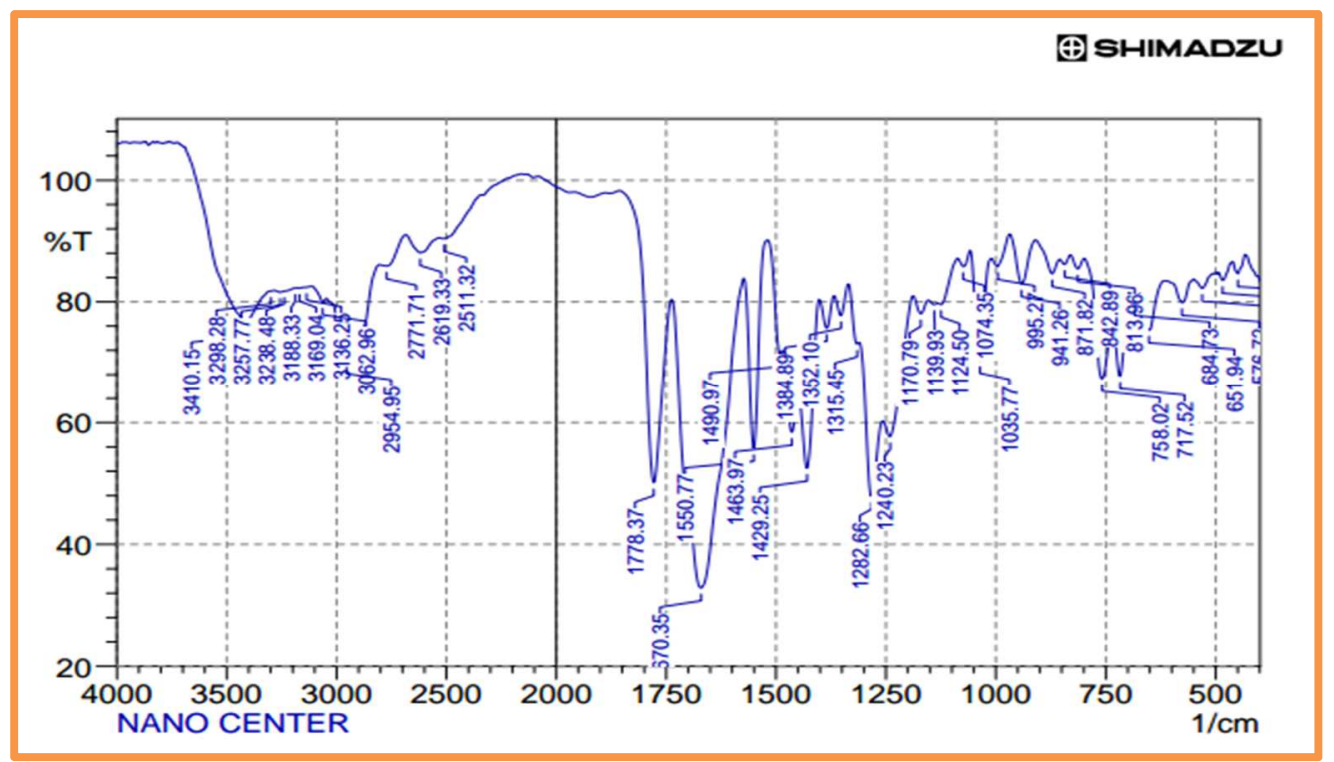

Fig. 17: FTIR spectrum of selected formula (F3)

\section{CONCLUSION}

It may be concluded from the results of this study that nanosuspensions of poorly soluble drug azilsartan medoxomil can be prepared using solvent antisolvent precipitation method and using PVP K30, Tween 80, and SLS as stabilizers. The process parameters, such as stabilizer concentration, stirring speed and combination of other stabilizer were investigated and optimized to produce the smallest drug nanoparticles. The dissolution rate of the nanosuspension significantly enhance as compare with the pure drug.

\section{ACKNOLEDGEMENT}

We are very thankful to the presidency of nanotechnology and advance material center in the university of technology, Iraq; for providing necessary facilities utilized in carrying out parts of the work.

\section{CONFLICT OF INTERESTS}

Declared none

\section{REFERENCES}

1. Limbachiya MI. Solubility enhancement techniques for poorly soluble drugs: a review. Int J Periodontics Restorative Dentistry 2011;4:71-86.

2. Williams HD, Trevaskis NL, Charman SA, Shanker RM, Charman WN, Pouton CW, et al. Strategies to address low drug solubility in discovery and development. Pharmacol Rev 2013;65:315-499.

3. Nagarwal RC, Kumar R, Dhanawat M, Das N, Pandit JK. Nanocrystal technology in the delivery of poorly soluble drugs: an overview. Curr Drug Delivery 2011;8:398-406.

4. Gad SC. Evaluating products for their potential to cause dermal and ocular irritation and corrosion. J Toxicol Cutan Ocul Toxicol 2002;21:213-44.

5. Amin K, Dannenfelser RM, Zielinski J, Wang B. Lyophilization of polyethylene glycol mixtures. J Pharm Sci 2004;93:2244-9.

6. Lakshmi P, Ashwini KG. Nanosuspension technology: a review. Int J Pharm Sci 2010;2:35-40.

7. Muller RH, Gohla S, Keck CM. State of the art of nanocrystalsspecial features, production, nanotoxicology aspects and intracellular delivery. Eur J Pharm Biopharm 2011;78:1-9. 
8. Moschwitzer JP. Drug nanocrystals in the commercial pharmaceutical development process. Int J Pharm 2013; 453:142-56

9. Priti M, Ruchira C, Ujwala D, Rohini C. Review: nanosuspension. Int J Pharm Sci Rev Res 2012;13:118-24.

10. Kesisoglou F, Amitava M. Crystalline nanosuspensions as potential toxicology and clinical oral formulations for BCS II/IV compounds. AAPS J 2012;14:677-87.

11. Pignatello R, Bucolo C, Spedalieri G, Maltese A, Puglisi G. Flurbiprofen loaded acrylate polymer nanosuspensions for ophthalmic application. Biomater Sci 2002;23:3247-55.

12. O'Neil MJ. Ed. The Merck Index-An encyclopedia of chemicals, drugs, and biological. Cambridge. 15th ed. UK: Royal Society of Chemistry; 2013. p. 161.

13. Kohara $\mathrm{Y}$, Kubo $\mathrm{K}$, Imamiya $\mathrm{E}$, Wada $\mathrm{T}$, Inada $\mathrm{Y}$, Naka $\mathrm{T}$. Synthesis and angiotensin II receptor antagonistic activities of benzimidazole derivatives bearing acidic heterocycles as novel tetrazole bioisosteres. J Med Chem 1996;39:5228-35.

14. Sheetal G, Rashmita D, Ravindra S. Solubility enhancement of azilsartan medoxomil by solid dispersion technique. Int J Inst Pharm Life Sci 2015;5:262-81.

15. Ramesh R, Jai D, Rohit R, Shweta K. Azilsartan: novel angiotensin receptor blocker. J Assoc Physicians India 2016;64:96-8.

16. Jones JD, Jackson SH, Agboton C, Martin TS. Azilsartan medoximil (edarbi). The eighth angiotensin II receptor blocker. PT 2011;36:634-40.

17. British national formally. edit $71 ; 2016$. p. 133.

18. Sweetman CS, Martindale. The Complete drug reference. 37ed. Pharmaceutical Press; 2011. p. 1345-6.

19. Kunal S, Ravindra B. UV spectrophotometric method for the estimation of azilsartan medoxomil in bulk and pharmaceutical formulations. World J Pharm Res 2015;4:1667-72.

20. Gandhi S, Mittal P, Pahade A, Rege S. Development and validation of stability indicating HPTLC method for estimation of azilsartan medoxomil. Pharm Sci Monitor 2015;6:224-32.

21. Kunal S, Ravindra B. Solubility enhancement of azilsartan medoxomel using mixed hydrotrophy. World J Pharm Pharm Sci 2015;4:1167-79.

22. Kumkum S, Bhawani S, Sonigar, Priyadarshani k, Ravindra K. A novel design and expansion of nanosuspension. Int J Appl Pharm Bio Res 2016;1:105-11.

23. Vikram M, Jayvadan K, Dhaval J. Formulation, optimization and characterization of simvastatin nanosuspension prepared by nanoprecipitation technique. Pharm Lett 2011;3:129-40.

24. Dandan L, Heming X, Baocheng T, Kun Y, Hao P, Shilin M, et al. Fabrication of carvedilol nanosuspensions through the antisolvent precipitation-ultrasonication method for the improvement of dissolution rate and oral bioavailability. AAPS Pharm Sci Tech 2012;13:295-304.

25. Shekunov BY, Chattopadhyay P, Tong H, Chow A. Particle size analysis in pharmaceutics: principles, methods and applications. Pharma Res 2007;24:203-27.

26. Rajalakshmi R, Venkataramudu T, Kumar R, Divya K, Kiranmayi $M$. Design and characterization of valsartan nanosuspension. Int J Pharmacother 2012;2:70-81.

27. Erol Y, Hans-Hubert. Design of a phytosphingo sine containing, positively-charged nanoemulsion as a colloidal carrier system for dermal application of ceramides. Eur J Pharm Biopharm 2005;60:91-8.

28. Nakarani M, Misra AK, Patel JK, Vaghani SS. Itraconazole nanosuspension for oral delivery: formulation, characterization and in vitro comparison with marketed formulation. Daru J Pharm Sci 2010;18:84-90.

29. Sahu BP, Das MK. Nanosuspension for enhancement of oral bioavailability of felodipine. Appl Nanosci 2013;4:1-9.

30. Dolenc A, Govedarica B, Dreu R, Kocbek P, Srcic S, Kristl J. Nanosized particles of orlistat with enhanced in vitro dissolution rate and lipase inhibition. Int $\mathrm{J}$ Pharm 2010;396:149-55.
31. Dubhi M, Ghodasara U, Mori D, Patel K, Manek R, Sheth NR. Formulation, optimization and characterization of candesartan cilexetil nanosuspension for in vitro dissolution enhancement Afr J Pharm Pharmacol 2015;9:102-13.

32. Ige PP, Baria RK, Gattani SG. Fabrication of fenofibrate nanocrystals by probe sonication method for enhancement of dissolution rate and oral bioavailability. Colloids Surf B 2013;108:366-73.

33. Raghad AN, Hind EZ. Enhancement of candesartan cilexetil dissolution rate by using different methods. Asian J Pharm Clin Res 2015;8:320-6.

34. Gandhi S, Mittal P, Pahade A, Rege S. Development and validation of stability indicating HPLC method for estimation of azilsartan medoxomil. Pharm Sci Monitor 2015 6:224-32.

35. Iswariya V, Soujanya G, Santhoshi S, Rani S, Haseeba, Sabitha. Formulation development and optimization of extend release matrix tablet of azilsartan medoxomil using natural and synthetic polymers. Eur j Pharm Med Res 2016;3:294-304.

36. Gao L, Zhang D, Chen M, Zheng T, Wang S. Preparation and characterization of an oridonin nanosuspension for solubility and dissolution velocity enhancement. Drug Dev Ind Pharm 2007;33:1332-9.

37. Kocbek P, Baumgartner S, Kristl J. Preparation and evaluation of nanosuspensions for enhancing the dissolution of poorly soluble drugs. Int J Pharm 2006;312:179-86.

38. Mcclements D. Crystals and crystallization in oil-in-water emulsions: implications for emulsion-based delivery systems. Adv Colloid Interface Sci 2012;174:1-30.

39. Helgason T, Awad TS, Kristbergsson K, McClements DJ, Weiss J. Effect of surfactant surface coverage on formation of solid lipid nanoparticles (SLN). J Colloid Interface Sci 2009;334:75-81.

40. Van Eerdenbrugh B, Vermant J, Martens JA, Froyen L, Van Humbeeck J, Augustijns P. A screening study of surface stabilization during the production of drug nanocrystals. J Pharm Sci 2009;98:2091-103.

41. Merisko-Liversidge E, Sarpotdar P, Bruno J, Hajj S, Wei L, Peltier $\mathrm{N}$, et al. Formulation and antitumor activity evaluation of nanocrystalline suspensions of poorly soluble anticancer drugs. Pharm Res 1996;13:272-8.

42. Patravale VB. Nanosuspensions: a promising drug delivery strategy. J Pharm Pharmacol 2004;56:827-40.

43. Wu L, Zhang J, Watanabe W. Physical and chemical stability of drug nanoparticles. Adv Drug Delivery Rev 2011;63:456-69.

44. Jenning V, Gohla S. Encapsulation of retinoids in solid lipid nanoparticles (SLN). J Microencapsulation 2001;18:149-58

45. Senthil Kumar P, Arivuchelvan A, Jagadeeswaran A, Subramanian N, Senthil Kumar C, Mekala P. Formulation, optimization and evaluation of enrofloxacin solid lipid nanoparticles for sustained oral delivery. Asian J Pharm Clin Res 2015;8:231-6.

46. Patil P, Bhoskar M. Optimization and evaluation of spray dried chitosan nanoparticles containing doxorubicin. Int J Curr Pharm Res 2014;6:7-15.

47. Bagul R, Mahajan V, Dhake A. New approaches in nanoparticulate drug delivery system-a review. Int J Curr Pharm Res 2012;4:29-38.

48. Mou D, Chen $\mathrm{H}$, Wan J, Xu H, Yang X. Potent dried drug nanosuspensions for oral bioavailability enhancement of poorly soluble drugs with $\mathrm{pH}$-dependent solubility. Int J Pharm 2011;413:237-44.

49. Mahapatra A, Murthy P. Solubility and dissolution rate enhancement of efavirenz by inclusion complexation and liquid anti-solvent precipitation technique. I Chem Pharm Res 2014;6:1099-106.

50. Tugba G, Reyhan N, Levent O. Design and characterization of nanocrystal formulations containing ezetimibe. Chem Pharm Bull 2011;59:41-5.

\section{How to cite this article}

- $\quad$ Nizar Awish Jassem, Nawal Ayash Rajab. Formulation and in vitro evaluation of azilsartan medoxomil nanosuspension. Int J Pharm Pharm Sci 2017;9(7):110-119. 